\title{
Mixed convection flow along an inclined permeable plate: effect of magnetic field, nanolayer conductivity and nanoparticle diameter
}

\author{
Puneet Rana $\cdot$ O. Anwar Bég
}

Received: 26 September 2013/ Accepted: 18 August 2014/Published online: 7 September 2014

(c) The Author(s) 2014. This article is published with open access at Springerlink.com

\begin{abstract}
Steady, two-dimensional mixed convection boundary layer flow of an incompressible $\mathrm{Al}_{2} \mathrm{O}_{3}$-water nanofluid along an inclined permeable plate in the presence of transverse magnetic field has been examined numerically. The governing equations (Boussinesq approximation) with associated boundary condition are solved using FEM for nanofluid containing spherical-shaped nanoparticles having volume fraction ranging from 1 to $4 \%$. Staticbased model for calculating the effective thermal conductivity at $300 \mathrm{~K}$, proposed by Leong et al. (J Nanopart Res $8: 245-254,2006$ ) and Murshed et al. (Int J Therm Sci 47:560-568, 2008) has been implemented. Effect of various pertinent parameters with different classical and experimental models for effective dynamic viscosity is discussed.
\end{abstract}

Keywords Nanofluid - Inclined plate - Mixed convection Static mechanism $\cdot$ FEM

\section{Introduction}

Nowadays, the heat transfer enhancement is one of the most challenging problems in different industrial applications and engineering systems. Choi (1995) was the first person to introduce fluids composed of nanometer-sized particles dispersed in a base fluid which are called as

\section{P. Rana $(\square)$}

Department of Mathematics, Jaypee Institute of Information

Technology, Noida, Uttar Pradesh, India

e-mail: puneetranaiitr@gmail.com

O. A. Bég

Gort Engovation-Propulsion, Nanomechanics and Biophysics, Southmere Avenue, Bradford BD73NU, UK nanofluids and disclosed the various advantages of the application of nanofluids, such as improved heat transfer, minimal clogging, size reduction of the heat transfer system, microchannel cooling, and miniaturization of systems in that study.

The classical theoretical approach for the conductivity measurement solid-fluid suspensions (Maxwell 1873; Hamilton and Crosser 1962) could not justify the experimental results in which the large enhancement of the thermal conductivity in case of low concentrations of nanoparticles. To overcome this limitations of classical theory, the new mechanisms have been first proposed by Wang et al. (2003) for the enhanced thermal transport in case of nanofluids, such as particle motion, surface action, and electro-kinetic effects. They suggested that nanoparticle size and nanolayer thermal conductivity are important parameters for enhancing the thermal conductivity of nanofluids. Later on, Xuan and Li (2000) recommended several possible mechanisms for enhanced thermal conductivity of nanofluids, such as the increased surface area of nanoparticles, particle-particle collisions and the dispersion of nanoparticles. Based on static mechanics, several attempts have been made to formulate appropriate effective thermal conductivity (Xue and Xu 2005; Leong et al. 2006; Tillman and Hill 2007; Murshed et al. 2008). Koo and Kleinstreuer (2004) stated that the effective thermal conductivity is composed of the particle's conventional static part and a Brownian motion part. Moreover, the Brownian motion effect was found to become more effective at higher temperature as observed experimentally.

The electrically conducting fluid flow past a heated surface under magnetic effects has attracted lot of researchers due to its many engineering applications such as in cooling of nuclear reactors, petroleum industries, 
MHD power generators, plasma studies etc. Abdelkhalek (2006) investigated the effects of mass transfer on steady two-dimensional laminar MHD mixed convection. Aydin and Kaya (2009a) discussed the magnetic field effect on about a permeable vertical flat plate. The combined effect of inclination and magnetic field in mixed convection flow has been discussed by Aydin and Kaya (2009b).

In case of nanofluid, Hamad (2011) investigated the effect of magnetic field effect on natural convection flow of a nanofluid over stretching sheet analytically. Later on, many researchers discussed the effect of magnetic field on different geometries with classical assumptions in the years 2011-2012. Recently, effect of nanofluid properties on magnetohydrodynamic pump (MHD) has been investigated by Shahidian et al. (2012). In their study, effect of thermal conductivity based on nanolayer concept has been taken into consideration for the case of $\mathrm{Al}_{2} \mathrm{O}_{3}$ nanofluid.

In the present chapter, we have simulated mixed convection flow of nanofluid along an inclined plate, using the static model introduced by Leong et al. (2006) and Murshed et al. (2008) for thermal conductivity of nanofluids at $300 \mathrm{~K}$. The effect of Brownian motion is assumed to be neglected at this moderate temperature. Both classical and experimental correlations for the viscosity of $\mathrm{Al}_{2} \mathrm{O}_{3}$-water nanofluid are implemented. The objective of the present chapter is to study the effect of magnetic field, nanoparticle diameter, nanolayer conductivity to base fluid conductivity ratio, inclination angle and nanoparticle volume fraction on the steady boundary layer nanofluid flow and heat transfer characteristics.

\section{Mathematical model}

In the present analysis, the steady, two-dimensional, incompressible laminar boundary layer flow of a $\mathrm{Al}_{2} \mathrm{O}_{3}$ water nanofluid past an inclined semi-infinite permeable flat plate with an angle $\delta$ has been taken. The flow is considered in the direction of $x$ axis along the inclined flat plate whereas the $y$ axis is taken normal to the plate. The surface of the flat plate is maintained at a constant temperature $\left(T_{w}\right)$ higher than the constant temperature $\left(T_{\infty}\right)$ of the ambient nanofluid. A magnetic field having uniform strength $B_{0}$ is applied in the $y$ direction, perpendicular to the plate and viscous dissipation term is ignored. Under the assumption of small magnetic Reynolds number, the induced magnetic field is considered to be zero. The thermal equilibrium and no slip have also been assumed between nanoparticles and base fluid. The geometry of the flow configuration is shown in Fig. 1. The boundary layer and Boussinesq approximations are assumed to be valid. The basic equations for nanofluids can be written as:

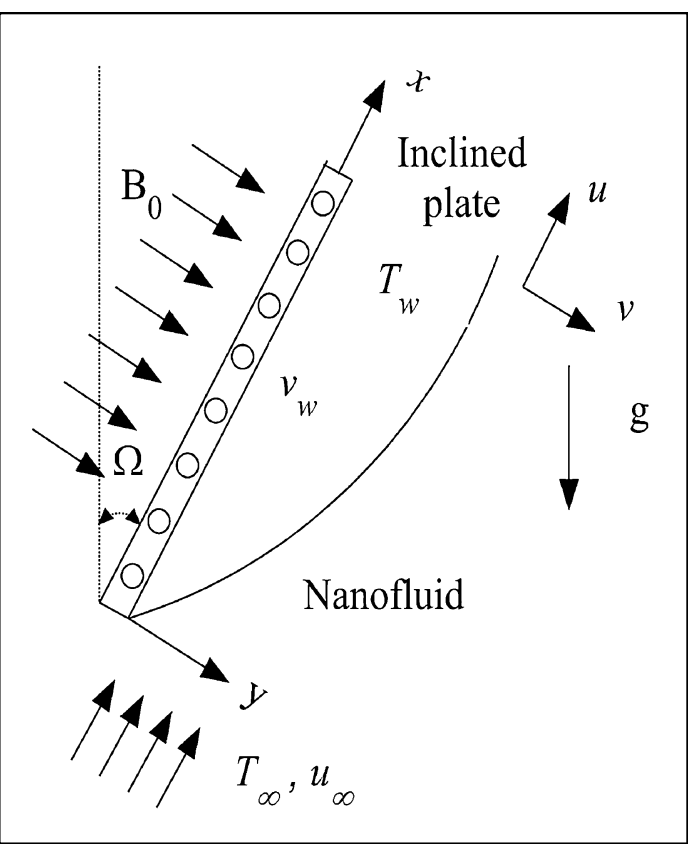

Fig. 1 Physical model and coordinate system

$$
\frac{\partial u}{\partial x}+\frac{\partial v}{\partial y}=0
$$

$$
\begin{aligned}
u \frac{\partial u}{\partial x}+v \frac{\partial u}{\partial y}= & \frac{1}{\rho_{n f}}\left[\mu_{n f} \frac{\partial^{2} u}{\partial y^{2}}+(\rho \beta)_{n f} g\left(T-T_{\infty}\right) \cos (\delta)\right. \\
& \left.-\sigma_{n f} B_{0}^{2}\left(u-u_{\infty}\right)\right]
\end{aligned}
$$

$u \frac{\partial T}{\partial x}+v \frac{\partial T}{\partial y}=\frac{1}{\left(\rho C_{p}\right)_{n f}}\left[k_{n f} \frac{\partial^{2} T}{\partial y^{2}}\right]$

subject to the boundary conditions

$$
\begin{aligned}
& x>0 \quad y=0 \quad T=T_{w} \quad u=0 \quad v= \pm V_{w}, \\
& x=0 \quad y>0 T=T_{\infty} \quad u=u_{\infty}, \\
& y \rightarrow \infty T=T_{\infty} u=u_{\infty} .
\end{aligned}
$$

\section{Effective viscosity models}

The three different viscosity models for nanofluids containing alumina particles $\left(\mathrm{Al}_{2} \mathrm{O}_{3}\right)$ are given below:

\section{Model I (classical)}

Model (I) attributed to Brinkman (1952) is as follows:

$\frac{\mu_{n f}}{\mu_{f}}=\frac{1}{(1-\phi)^{2.5}}$.

Wang et al. (2003) experimentally observed that the $\mathrm{Al}_{2} \mathrm{O}_{3}$-water mixture shows an increase of viscosity between 20 and $30 \%$ for $3 \%$ vol. $\mathrm{Al}_{2} \mathrm{O}_{3}$ solutions as compared to water alone. 


\section{Model II}

The experimental correlation for $\mathrm{Al}_{2} \mathrm{O}_{3}$-water (Model II) is as follows (Wang et al. 2003):

$\frac{\mu_{n f}}{\mu_{f}}=1+7.3 \phi+123 \phi^{2}$.

The $\mathrm{Al}_{2} \mathrm{O}_{3}$-water viscosity observed by Pak and Cho (1998) was higher than that of water as compared to Wang et al. (2003).

\section{Model III}

Pak and Cho (1998) correlation for the viscosity of $\mathrm{Al}_{2} \mathrm{O}_{3}-$ water nanofluid is as follows:

$\frac{\mu_{n f}}{\mu_{f}}=1+39.11 \phi+533.9 \phi^{2}$.

The physical properties of the nanofluid are as Oztop and Abu-Nada (2008) and Tiwari and Das (2007):

$$
\begin{aligned}
\rho_{n f} & =(1-\phi) \rho_{f}+\phi \rho_{p}, \\
(\rho \beta)_{n f} & =(1-\phi)(\rho \beta)_{f}+\phi(\rho \beta)_{p}, \\
\left(\rho C_{p}\right)_{n f} & =(1-\phi)\left(\rho C_{p}\right)_{f}+\phi\left(\rho C_{p}\right)_{p} .
\end{aligned}
$$

Effective thermal conductivity model

The existing classical models (Maxwell 1873; Hamilton and Crosser 1962) are found to be incapable to anticipate the anomalously high thermal conductivity of nanofluids. This is due to reason that classical models do not incorporate the effects of particle size, the particle/liquid interfacial layer and distribution which are considered as significant mechanisms for enhanced thermal conductivity of nanofluids.

Effective thermal conductivity for spherical-shaped nanoparticles can be incorporated from the following expression (Leong et al. 2006; Murshed et al. 2008):

$k_{n f}=$

$\frac{k_{l r} \phi\left(k_{p}-k_{l r}\right)\left[2 \gamma_{2}^{3}-\gamma_{1}^{3}+1\right]+\left(k_{p}+2 k_{l r}\right) \gamma_{2}^{3}\left[\phi \gamma_{1}^{3}\left(k_{l r}-k_{f}\right)+k_{f}\right]}{\gamma_{2}^{3}\left(k_{p}+2 k_{l r}\right)-\left(k_{p}-k_{l r}\right) \phi\left(\gamma_{2}^{3}+\gamma_{1}^{3}-1\right)}$,

where, $\gamma_{1}=1+\left(2 * \widehat{h} / d_{p}\right), \quad \gamma_{2}=1+\left(\widehat{h} / d_{p}\right), \widehat{h}$ is the interfacial thickness at the surface. The interfacial layer thermal conductivity can be represented as $k_{l r}=\omega k_{f}$, where $\omega>1$ is an empirical parameter (Leong et al. 2006; Murshed et al. 2008). Thus, we get,

$$
\begin{aligned}
& \frac{k_{n f}}{k_{f}}= \\
& \frac{\omega \phi\left(k_{p}-\omega k_{f}\right)\left[2 \gamma_{2}^{3}-\gamma_{1}^{3}+1\right]+\left(k_{p}+2 \omega k_{f}\right) \gamma_{2}^{3}\left[\phi \gamma_{1}^{3}(\omega-1)+1\right]}{\gamma_{2}^{3}\left(k_{p}+2 \omega k_{f}\right)-\left(k_{p}-\omega k_{f}\right) \phi\left(\gamma_{2}^{3}+\gamma_{1}^{3}-1\right)},
\end{aligned}
$$

Hashimoto et al. (1980) demonstrated the interfacial layer thickness on the basis of electron density at interface, which is given as $\widehat{h}=\sqrt{2 \pi} \hat{\sigma}$, where $\widehat{\sigma}$ is a parameter which quantifies interfacial boundary diffusioness and for spherical particle its value is $1 \mathrm{~nm}$.

Introducing the following non-dimensional variables:

$$
\begin{gathered}
\xi=\frac{x}{L}, \quad \psi(x, y)=\left(v_{f} u_{\infty} x\right)^{1 / 2} f(\xi, \eta), \\
\eta=y\left(\frac{u_{\infty}}{v_{f} x}\right)^{1 / 2}, \theta(\eta)=\frac{T-T_{\infty}}{T_{w}-T_{\infty}},
\end{gathered}
$$

where $\psi(x, y)$ represents free stream function that satisfies the Cauchy-Riemann Equation with $u=\frac{\partial \psi}{\partial y}$ and $\mathrm{v}=-\frac{\partial \psi}{\partial \mathrm{x}}$, the velocity components can be reduced as:

$$
u=u_{\infty} f^{\prime}, v=-\left(\frac{v_{f} u_{\infty}}{x}\right)^{1 / 2}\left\{\frac{1}{2} f+\xi \frac{\partial f}{\partial \xi}-\frac{\eta}{2} f^{\prime}\right\} .
$$

The transformed momentum and energy equations (2) and (3) can be written as:

$$
\begin{gathered}
\frac{1}{\left(1-\phi+\phi \rho_{p} / \rho_{f}\right)}\left\{\begin{array}{c}
\left(\frac{\mu_{n f}}{\mu_{f}}\right) f^{\prime \prime \prime}+\left[1-\phi+\phi(\rho \beta)_{p} /(\rho \beta)_{f}\right] R i \xi \theta \cos (\delta) \\
-M \xi\left(f^{\prime}-1\right)
\end{array}\right\} \\
+\frac{1}{2} f f^{\prime \prime}=\xi\left(f^{\prime} \frac{\partial f^{\prime}}{\partial \xi}-f^{\prime \prime} \frac{\partial f}{\partial \xi}\right), \\
\frac{1}{\left(1-\phi+\phi\left(\rho C_{p}\right)_{p} /\left(\rho C_{p}\right)_{f}\right)}\left[\frac{1}{\operatorname{Pr}}\left(\frac{k_{n f}}{k_{f}}\right) \theta^{\prime \prime}\right]+f \theta^{\prime}=\xi\left(f^{\prime} \frac{\partial \theta}{\partial \xi}-\theta^{\prime} \frac{\partial f}{\partial \xi}\right),
\end{gathered}
$$

The transformed boundary conditions are:

$f(\xi, 0)+2 \xi \frac{\partial f}{\partial \xi}=f_{w} \xi^{1 / 2}, f^{\prime}(\xi, 0)=0, \quad \theta(\xi, 0)=1$, $f^{\prime}(\xi, \infty)=1, \theta(\xi, \infty)=0$.

where prime denotes the differentiation w.r.t. $\eta$.

The important parameters, dictating the flow dynamics are defined by:

$$
\begin{aligned}
& \operatorname{Pr}=\frac{\mu C_{p}}{k}=\frac{v_{f}}{\alpha}, \quad R i=\frac{G r}{\operatorname{Re}^{2}}, \quad G r=\frac{g_{e} \beta\left(T_{w}-T_{\infty}\right) L^{3}}{v_{f}^{2}} \\
& \operatorname{Re}=\frac{u_{\infty} L}{v_{f}}, \quad H a=\frac{\sigma B_{0}^{2} L^{2}}{\mu}, \quad M=H a / \operatorname{Re}, f_{w}=-2 \frac{L}{v_{f}} V_{w} \operatorname{Re}^{-1 / 2} .
\end{aligned}
$$

The local skin friction coefficient and the local Nusselt number are given as:

$$
\begin{aligned}
C f_{x} & =\mu_{n f}\left(\frac{\partial u}{\partial y}\right)_{y=0} / \rho_{f} u_{\infty}^{2}=\left(\operatorname{Re}_{x}\right)^{-1 / 2} \frac{\mu_{n f}}{\mu_{f}} f^{\prime \prime}(0), \\
C_{f} & =\left(\operatorname{Re}_{x}\right)^{1 / 2} C f_{x}=\frac{\mu_{n f}}{\mu_{f}} f^{\prime \prime}(0), \\
N u_{x} & =-\left(\frac{k_{n f}}{k_{f}}\right)\left(\frac{\partial T}{\partial y}\right)_{y=0} /\left(T_{w}-T_{\infty}\right)=-\left(\operatorname{Re}_{x}\right)^{1 / 2}\left(\frac{k_{n f}}{k_{f}}\right) \theta^{\prime}(0), \\
N u & =\left(\operatorname{Re}_{x}\right)^{-1 / 2} N u_{x}=-\left(\frac{k_{n f}}{k_{f}}\right) \theta^{\prime}(0),
\end{aligned}
$$


where $C_{f}$ and $\mathrm{Nu}$ are modified skin friction and Nusselt number, respectively.

Finally, the average Nusselt number is determined from:

$\mathrm{Nu}_{\mathrm{avg}}=\left(\frac{1}{\mathrm{~L}}\right) \int_{0}^{\mathrm{L}} \mathrm{Nu}(\xi) \mathrm{d} \xi$,

where, $L=$ characteristic length of plate. Simpson's $1 / 3$ rule of integration is implemented.

\section{Finite element solution}

Finite element method (FEM) was basically developed in reference to structural problems, but now it has been used as a mathematical tool for solving the linear and non-linear ordinary or partial differential equations as well as integral equations. The finite element method not only overcomes the shortcoming of the traditional variational methods, it is also endowed with the features of an effective computational technique. This method is so general that it can be applied to a wide variety of engineering problems, including heat transfer (Bhargava and Rana 2011; Rana et al. 2012), fluid mechanics (Rana and Bhargava 2011; Rana et al. 2013), rigid body dynamics (Dettmer 2006), solid mechanics (Hansbo and Hansbo 2004) and many other fields.

Finite element formulation

Let the domain be divided into quadratic rectangular elements $\Omega_{e}$. The finite element model may be obtained by substituting finite element approximations of the form:

$f=\sum_{j=1}^{9} f_{j} N_{j}(\xi, \eta), \quad h=\sum_{j=1}^{9} h_{j} N_{j}(\xi, \eta), \quad \theta=\sum_{j=1}^{9} \theta_{j} N_{j}(\xi, \eta)$

with $w_{1}=w_{2}=w_{3}=N_{j} \quad(j=1,2,3)$ where $N_{j}(\xi, \eta)$ are the quadratic interpolation functions for a rectangular element $\Omega_{e}$ as follows: The finite element model of the equations thus formed is given by

$$
\left[\begin{array}{lll}
{\left[K^{11}\right]} & {\left[K^{12}\right]} & {\left[K^{13}\right]} \\
{\left[K^{21}\right]} & {\left[K^{22}\right]} & {\left[K^{23}\right]} \\
{\left[K^{31}\right]} & {\left[K^{32}\right]} & {\left[K^{33}\right]}
\end{array}\right]\left[\begin{array}{l}
\{f\} \\
\{h\} \\
\{\theta\}
\end{array}\right]=\left[\begin{array}{l}
\left\{b^{1}\right\} \\
\left\{b^{2}\right\} \\
\left\{b^{3}\right\}
\end{array}\right]
$$

where $\left[K^{m n}\right]$ and $\left[b^{m}\right](m, n=1,2,3)$ are the matrices of order $3 \times 3$ and $3 \times 1$, respectively, and therefore each element matrix is of the order $9 \times 9$. All the matrices are defined as follows:

$$
\begin{aligned}
& K_{i j}^{11}=\int_{\Omega_{e}} N_{i} \frac{\partial N_{j}}{\partial \eta} \mathrm{d} \Omega_{e}, \quad K_{i j}^{12}=-\int_{\Omega_{e}} N_{i} N_{j} \mathrm{~d} \Omega_{e}, K_{i j}^{13}=0, \\
& K_{i j}^{21}=\int_{\Omega_{e}}\left\{N_{i} \xi \frac{\partial \bar{h}}{\partial \eta} \frac{\partial N_{j}}{\partial \xi}+\left(\frac{1}{2}\right) N_{i} N_{j} \frac{\partial \bar{h}}{\partial \eta}\right\} \mathrm{d} \Omega_{e}, \\
& K_{i j}^{22}=-\frac{1}{\left(1-\phi+\phi \rho_{s} / \rho_{f}\right)}\left(\frac{\mu_{n f}}{\mu_{f}}\right) \int_{\Omega_{e}} \frac{\partial N_{i}}{\partial \eta} \frac{\partial N_{j}}{\partial \eta} \mathrm{d} \Omega_{e} \\
& -\int_{\Omega_{e}} N_{i} \xi N_{j} \frac{\partial \bar{h}}{\partial \xi} \mathrm{d} \Omega_{e}-M \int_{\Omega_{e}} N_{i} \xi N_{j} \mathrm{~d} \Omega_{e} \\
& K_{i j}^{23}=\left(\frac{1-\phi+\phi(\rho \beta)_{s} /(\rho \beta)_{f}}{1-\phi+\phi \rho_{s} / \rho_{f}}\right) \operatorname{Ri} \int_{\Omega_{e}} N_{i} \xi N_{j} \mathrm{~d} \Omega_{e}, \\
& K_{i j}^{31}=\int_{\Omega_{e}} N_{i} \frac{\partial \bar{\theta}}{\partial \eta} N_{j} d \Omega_{e}+\int_{\Omega_{e}} \xi N_{i} \frac{\partial \bar{\theta}}{\partial \eta} \frac{\partial N_{j}}{\partial \xi} \mathrm{d} \Omega_{e} \\
& K_{i j}^{32}=-\int_{\Omega_{e}} N_{i} \xi N_{j} \frac{\partial \bar{\theta}}{\partial \xi} \mathrm{d} \Omega_{e} \\
& K_{i j}^{33}=\frac{1}{\left(1-\phi+\phi\left(\rho C_{p}\right)_{s} /\left(\rho C_{p}\right)_{f}\right)}\left(\frac{1}{\operatorname{Pr}}\left(\frac{k_{n f}}{k_{f}}\right) \int_{\Omega_{e}} \frac{\partial N_{i}}{\partial \eta} \frac{\partial N_{j}}{\partial \eta} \mathrm{d} \Omega_{e}\right) \\
& b_{i}^{1}=0, b_{i}^{2}=-\frac{1}{\left(1-\phi+\phi \rho_{s} / \rho_{f}\right)} \\
& \times\left[\left(\frac{\mu_{n f}}{\mu_{f}}\right) \oint_{\Gamma_{e}} N_{i} q_{n_{2}} \mathrm{~d} s+M \oint_{\Gamma_{e}} \xi N_{i} q_{n_{2}} \mathrm{~d} s\right] \\
& b_{i}^{3}=-\frac{1}{\operatorname{Pr}} \frac{1}{\left(1-\phi+\phi\left(\rho C_{p}\right)_{s} /\left(\rho C_{p}\right)_{f}\right)}\left(\frac{k_{n f}}{k_{f}}\right) \oint_{\Gamma_{e}} N_{i} q_{n_{3}} \mathrm{~d} s,
\end{aligned}
$$

where

$$
\begin{gathered}
\bar{h}=\sum_{i=1}^{9} \overline{h_{i}} N_{i}, \quad \bar{f}=\sum_{i=1}^{9} \overline{f_{i}} N_{i}, \quad \bar{\theta}=\sum_{i=1}^{9} \overline{\theta_{i}} N_{i}, \\
\frac{\partial \bar{h}}{\partial \eta}=\sum_{i=1}^{9} \overline{h_{i}} \frac{\partial N_{i}}{\partial \eta}, \quad \frac{\partial \bar{h}}{\partial \xi}=\sum_{i=1}^{9} \overline{h_{i}} \frac{\partial N_{i}}{\partial \bar{\xi}}, \quad \frac{\partial \bar{\theta}}{\partial \xi}=\sum_{i=1}^{9} \overline{\theta_{i}} \frac{\partial N_{i}}{\partial \bar{\xi}}
\end{gathered}
$$

Since the interpolation functions are easily derivable for a rectangular elements. Thus, we transform the finite element integral statements defined over quadrilaterals to a rectangle. Similar procedure has been followed for the rectangular element. For example, a nine-node quadratic elements with each element mapped using isoparametric mapping (Reddy 1985; Rana et al. 2013) from $\xi-\eta$ domain $\left(\Omega_{e}\right)$ to a unit square $\xi^{\prime}-\eta^{\prime}$ domain $\left(\Omega^{0}\right)$ is shown in Fig. 2. Thus, the integral is transferred from problem coordinate system $(\xi, \eta)$ to specific coordinate system $\left(\xi^{\prime}, \eta^{\prime}\right)$ (master element).

$$
\xi=\sum_{i=1}^{9} \xi_{i} N_{i}\left(\xi^{\prime}, \eta^{\prime}\right), \quad \eta=\sum_{i=1}^{9} \eta_{i} N_{i}\left(\xi^{\prime}, \eta^{\prime}\right)
$$




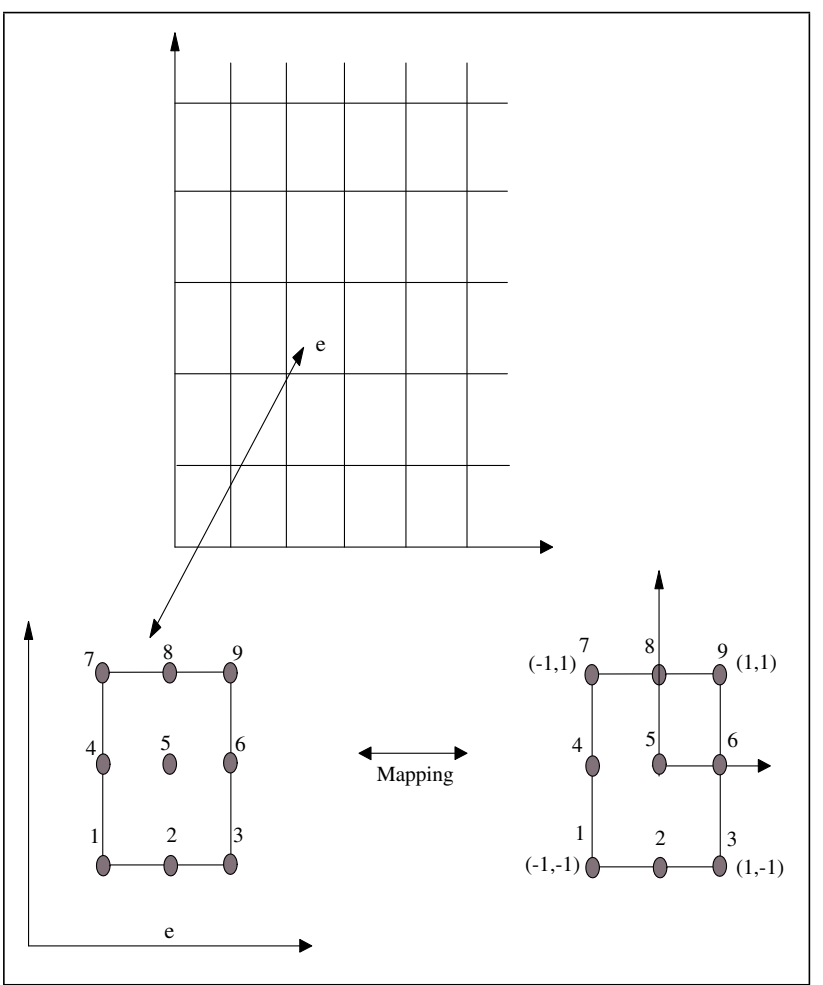

Fig. 2 Mapping of master rectangular element to a rectangular element of a finite element mesh

where $N_{i}\left(\xi^{\prime}, \eta^{\prime}\right)$ are the local biquadratic basis functions on the $\left(\xi^{\prime}, \eta^{\prime}\right)$ domain. The integrals can be evaluated in $\left(\xi^{\prime}, \eta^{\prime}\right)$ domain using following relationships:

$$
\begin{aligned}
& \left\{\begin{array}{l}
\frac{\partial N_{i}}{\partial \xi^{\prime}} \\
\frac{\partial N_{i}}{\partial \eta^{\prime}}
\end{array}\right\}=[J]\left\{\begin{array}{l}
\frac{\partial \psi_{i}}{\partial \xi} \\
\frac{\partial \psi_{i}}{\partial \eta}
\end{array}\right\} \text { where } \\
& J=\left[\begin{array}{ll}
\frac{\partial \xi}{\partial \xi^{\prime}} & \frac{\partial \eta}{\partial \xi^{\prime}} \\
\frac{\partial \xi}{\partial \eta^{\prime}} & \frac{\partial \eta}{\partial \eta^{\prime}}
\end{array}\right] \text { is the Jacobian matrix } \\
& \left\{\begin{array}{c}
\frac{\partial N_{i}}{\partial \xi} \\
\frac{\partial N_{i}}{\partial \eta}
\end{array}\right\}=[J]^{-1}\left\{\begin{array}{l}
\frac{\partial N_{i}}{\partial \xi^{\prime}} \\
\frac{\partial N_{i}}{\partial \eta^{\prime}}
\end{array}\right\}, d A=J d \xi d \eta
\end{aligned}
$$

The necessary condition for $[J]^{-1}$ is that the determinant $J$, called Jacobian $J$ should be non-zero at every point $\left(\xi^{\prime}, \eta^{\prime}\right)$.

\section{Results and discussion}

Comprehensive numerical computations are conducted for various values of the parameters that describe the flow characteristics and the results are illustrated graphically. A numerical study is made to see the effect of different controlling parameter on $\mathrm{Al}_{2} \mathrm{O}_{3}$-water nanofluid with thermophysical properties shown in Table 1 . Moreover,
Table 1 Thermophysical properties of water and nanoparticles

\begin{tabular}{llcll}
\hline & $\begin{array}{l}\rho \\
\left(\mathrm{kg} / \mathrm{m}^{3}\right)\end{array}$ & $\begin{array}{l}C_{p} \\
(\mathrm{~J} / \mathrm{kg} \mathrm{K})\end{array}$ & $\begin{array}{l}k \\
(\mathrm{~W} / \mathrm{m} \mathrm{K})\end{array}$ & $\begin{array}{l}\beta \times 10^{-5} \\
(/ \mathrm{K})\end{array}$ \\
\hline Pure water & 997.1 & 4,179 & 0.613 & 21 \\
Alumina $\left(\mathrm{Al}_{2} \mathrm{O}_{3}\right)$ & 3,970 & 765 & 40 & 0.85 \\
\hline
\end{tabular}

Table 2 Grid independence study for different models of viscosity keeping $\mathrm{Ri}=1, M=1, d_{p}=5 \mathrm{~nm}, \operatorname{Pr}=6.2, \omega=10, \phi=0.04$

\begin{tabular}{lllll}
\hline Biquadratic elements & \multicolumn{4}{l}{$\mathrm{Nu}_{\text {avg }}$} \\
\cline { 2 - 5 } & Pure water & Model I & Model II & Model III \\
\hline $10 \times 10$ & 0.7910 & 1.3820 & 1.3314 & 1.2115 \\
$10 \times 20$ & 0.8066 & 1.4096 & 1.3581 & 1.2355 \\
$20 \times 20$ & 0.8379 & 1.4653 & 1.4117 & 1.2837 \\
$20 \times 40$ & 0.8442 & 1.4765 & 1.4225 & 1.2934 \\
$30 \times 40$ & 0.8487 & 1.4839 & 1.4297 & 1.2999 \\
$40 \times 50$ & 0.8533 & 1.4933 & 1.4407 & 1.3109 \\
$40 \times 80$ & 0.8569 & 1.4989 & 1.4442 & 1.3128 \\
$50 \times 80$ & 0.8574 & 1.4993 & 1.4449 & 1.3135 \\
\hline
\end{tabular}

Table 3 Comparison of results for Nusselt number $\left(-\theta^{\prime}(0,0)\right)$ for various $\operatorname{Pr}$ keeping $R i=0$ and $\phi=0$

\begin{tabular}{lllll}
\hline Pr & $\begin{array}{l}\text { Nield and } \\
\text { Kuznetsov (2003) }\end{array}$ & $\begin{array}{l}\text { Chamkha } \\
\text { et al. (2003) }\end{array}$ & $\begin{array}{l}\text { Aydin and } \\
\text { Kaya (2009a) }\end{array}$ & $\begin{array}{l}\text { Present } \\
\text { results }\end{array}$ \\
\hline 0.01 & - & 0.051830 & 0.051437 & 0.051301 \\
0.1 & 0.1580 & 0.142003 & 0.148123 & 0.147901 \\
1 & 0.3320 & 0.332173 & 0.332000 & 0.331980 \\
10 & 0.7300 & 0.728310 & 0.727801 & 0.727800 \\
100 & 1.5700 & 1.572180 & 1.573141 & 1.573140 \\
\hline
\end{tabular}

Table 4 Comparison of results for reduced Nusselt number $-\theta^{\prime}(0,0)$ for various $\operatorname{Pr}$ at $R i=0, \phi=0$

\begin{tabular}{lllllll}
\hline $\operatorname{Pr}$ & $\xi$ & $\begin{array}{l}\text { Yih } \\
(1999)\end{array}$ & $\begin{array}{l}\text { Chamkha } \\
\text { et al. } \\
(2003)\end{array}$ & $\begin{array}{l}\text { Watanabe } \\
\text { and Pop } \\
(1994)\end{array}$ & $\begin{array}{l}\text { Aydin and } \\
\text { Kaya } \\
(2009 a)\end{array}$ & $\begin{array}{l}\text { Present } \\
\text { results }\end{array}$ \\
\hline 0.733 & 0.0 & 0.297526 & 0.29760 & 0.29755 & 0.29753 & 0.297506 \\
& 0.5 & 0.357022 & 0.35704 & 0.35699 & 0.35709 & 0.356520 \\
& 1.0 & 0.382588 & 0.38319 & 0.38336 & 0.38363 & 0.389246 \\
& 1.5 & 0.398264 & 0.39998 & 0.39959 & 0.40012 & 0.400020 \\
& 2.0 & 0.409168 & 0.40945 & 0.41091 & 0.41134 & 0.411600 \\
1.0 & 0.0 & 0.332057 & 0.33217 & 0.33206 & 0.33206 & 0.332037 \\
& 0.5 & 0.402864 & 0.40310 & 0.40280 & 0.40259 & 0.402475 \\
& 1.0 & 0.433607 & 0.43390 & 0.43446 & 0.43460 & 0.434221 \\
& 1.5 & 0.452634 & 0.45280 & 0.45413 & 0.45302 & 0.454270 \\
& 2.0 & 0.465987 & 0.46611 & 0.46798 & 0.46612 & 0.466261 \\
\hline
\end{tabular}


velocity and temperature profiles of nanofluid are compared with pure water.

An extensive mesh testing has been conducted to ensure a grid- independence solution of given boundary value problem. The present code has been tested for grid independence by calculating the average Nusselt number on the plate. Different combinations of bi- quadratic elements for both pure water and $\mathrm{Al}_{2} \mathrm{O}_{3}$-water keeping $R i=1, M=1$, $d_{p}=5 \mathrm{~nm}, \operatorname{Pr}=6.2, \omega=10, \phi=0.04$ are also explored as shown in Table 2. In the case of $\mathrm{Al}_{2} \mathrm{O}_{3}$-water, average Nusselt number $\left(\mathrm{Nu}_{\mathrm{avg}}\right)$ of different models has been also shown. Further, the validity of the present numerical code has been assured for a limiting case. Tables 3 and 4 show that an excellent correlation has been achieved with the earlier results of Watanabe and Pop (1994), Yih (1999), Chamkha et al. (2003) and Aydin and Kaya (2007).

For obtaining the numerical solutions, the suitable guess value of $\xi_{\max }$ (length of the plate) and $\eta_{\max }$ (length of the domain) has been chosen which satisfy all boundary conditions. It has been observed that for the moderate values of $\eta_{\max }(>5.0)$, there is no appreciable effect on the results. Therefore, for computational purpose infinity has been set as 5.0. However, for $\xi_{\max }$, the results are obtained even for large $\xi_{\max }$ (up to 8); but for demonstration purpose, the results are shown only for $0 \leq \xi \leq 2.0$.

The entire flow domain contains 13,041 grid points. At each node, three functions are to be evaluated; hence after assembly of the element equations, we obtain a system of 39,123 equations which are non-linear. Therefore, an iterative scheme has been employed in the solution. After imposing the boundary conditions, a system of 38,818 equations have been solved with an accuracy of $10^{-4}$. The iterative process is terminated when the following condition is satisfied:

$\sum_{i, j}\left|\Theta_{i, j}^{m}-\Theta_{i, j}^{m-1}\right| \leq 10^{-4}$

where, $\Theta$ stands for either $f, h$ or $\theta$, and $m$ denotes the iterative step.

Gaussian quadrature is implemented for solving the integrations. Excellent convergence has been achieved.

In Fig. 3, the effective dynamic viscosity of $\mathrm{Al}_{2} \mathrm{O}_{3}-$ water nanofluid has been plotted against nanoparticle volume fraction for different models. It has been noted from correlation that viscosity measured from experiments (Wang et al. 1999; Pak and Cho 1998) is far different from classical predictions (Maxwell 1873; Hamilton and Crosser 1962). Figure 4 shows the characteristic of the effective thermal conductivity, which is a function of nanolayer to base fluid conductivity ratio $\left(\omega=k_{l r} / k_{f}\right)$ and nanoparticle diameter $\left(d_{p}\right)$. $\omega$ has relatively high effect for small

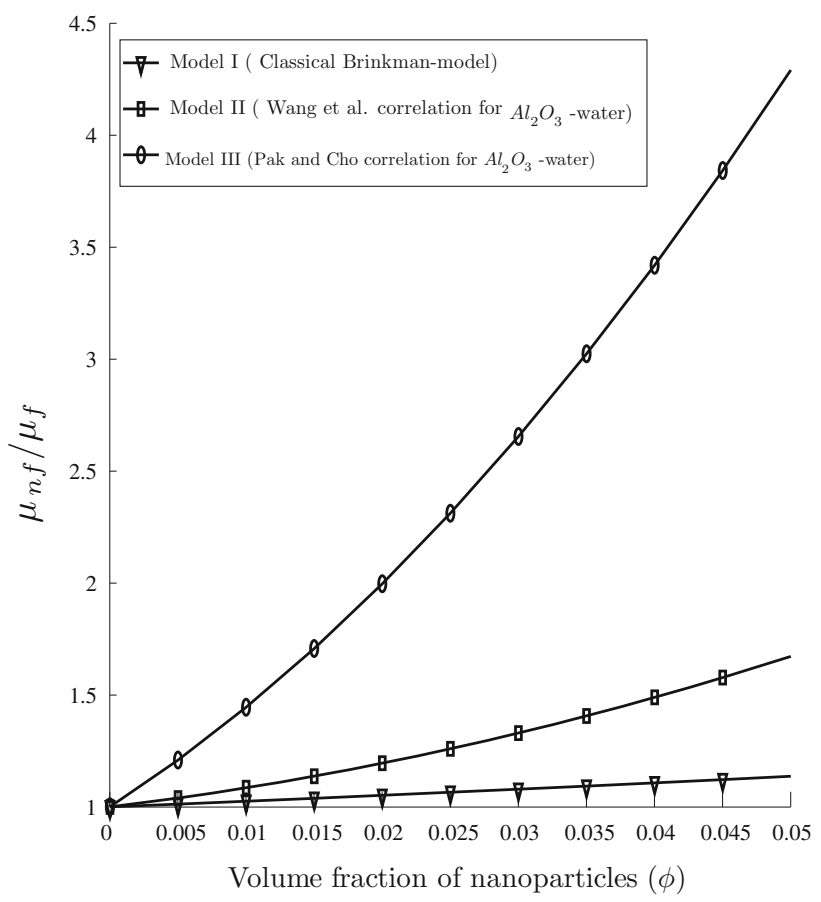

Fig. 3 Comparison of viscosity models

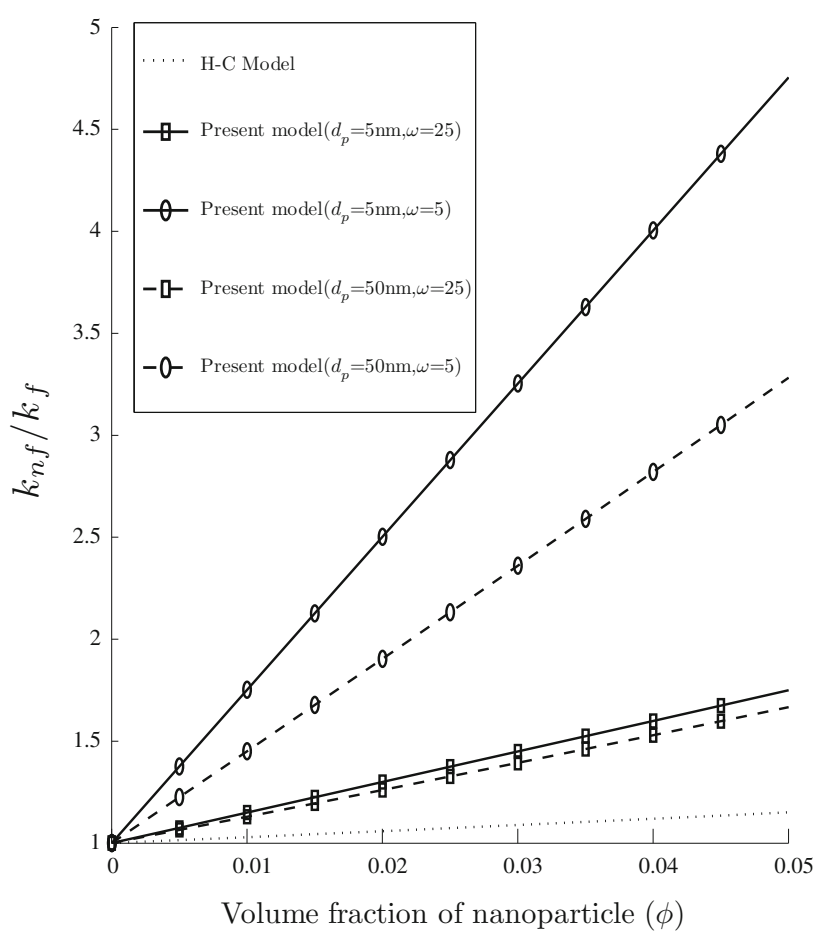

Fig. 4 Comparison of thermal conductivity models

nanoparticle diameters. Consequently, the presence of nanoparticles has a strong effect on thermal conductivity of the nanofluid for small nanoparticle diameters and high 
nanolayer to base fluid conductivity ratio. Thus, compared with the traditional $\mathrm{H}-\mathrm{C}$ model, the present model (Leong et al. 2006; Murshed et al. 2008) shows a better flexibility in predicting the heat transfer characteristic.

Selected computations are presented in Figs. 5, 6, 7, 8, 9, 10, 11 and 12. The following ranges of the main parameters are considered: $0.01 \leq \mathrm{Ri} \leq 10.0,1.0 \leq$ $M \leq 10.0,1 \leq d_{p}(\mathrm{~nm}) \leq 50,5.0 \leq \omega\left(k_{l r} / k_{f}\right) \leq 50.0$, Models I-III, $0 \leq \phi \leq 0.04, \operatorname{Pr}=6.2, \mathrm{Al}_{2} \mathrm{O}_{3}$-water. In all cases, default values of the governing parameters are: $\mathrm{Ri}=1.0, \operatorname{Pr}=6.2, M=1.0, d_{p}=5 \mathrm{~nm}, \omega=10, \mathrm{Al}_{2} \mathrm{O}_{3}-$ water with Model I, unless otherwise stated. The thermophysical properties of the nanofluid at $300 \mathrm{~K}$ are given in Table 2 (Hamad 2011).

\section{Effect of magnetic field parameter}

The effect of magnetic field parameter $(M)$ on velocity profile $f^{\prime}(\xi, \eta)$ and temperature profile $\theta(\xi, \eta)$ is shown in Fig. 5a, b, respectively. The effect of the magnetic field parameter $(M)$ has been explained from Eq. (2), the sign of the last term in the right hand side of Eq. (2). For the forced convection regime, this term $\frac{\sigma B_{0}^{2}}{\rho}\left(u-u_{\infty}\right)$ will always be negative since $u_{\infty}>u$. Thus, a force will aid in the direction of main flow. On the other hand, in case of free convection regime, when $R i \rightarrow \infty$, buoyancy-driven flow will dominate the external flow regime, hence the above term will be positive because $u_{\infty}<u$, which will diminish the main flow regime. This term has been resolved into two components: The first component, $\frac{\sigma B_{0}^{2}}{\rho} u_{\infty}$, represents the imposed pressure force, whereas the second component, $\frac{\sigma B_{0}^{2}}{\rho} u$, represents the Lorentz force which slows down the fluid motion in the boundary layer region. When the imposed pressure force overcomes the Lorentz force $\left(u_{\infty}<u\right)$, the effect of the magnetic parameter increases the velocity. Similarly, when the Lorentz force which slows the fluid motion dominates the imposed pressure force $\left(u_{\infty}<u\right)$, the effect of the magnetic parameter $(M)$ decreases velocity flow and hence it decreases both momentum and thermal boundary layer thickness (i.e., increases the velocity and temperature gradient at the wall). Similar results have been observed by Aydin and Kaya (2009a). Moreover, further addition of nanoparticles (increase in volume fraction) increases both velocity and temperature gradient. As magnetic parameter $(M)$ is multiplied by $\xi$, which leads to increase in velocity and temperature in the boundary layer, as we go away from the leading edge.

The effect of the magnetic parameter $(M)$ on the modified skin friction and Nusselt number is shown in Fig. 5c, $\mathrm{d}$, respectively. Both the skin friction and the Nusselt number increase with an increase in the magnetic parameter $(M)$. This is associated with an increase in the magnitude of wall velocity and temperature gradients.

Effect of nanoparticle diameter

The effect of the nanoparticle diameter on velocity profile $f^{\prime}((\xi, \eta))$ and temperature profile $(\theta(\xi, \eta))$ is shown in Fig. 6a, b, respectively. The addition of nanoparticles decreases the momentum boundary layer and increases the thermal boundary layer, however, this behavior is more pronouncing for small size nanoparticles. The small size nanoparticle $\left(d_{p}=1 \mathrm{~nm}\right)$ increases the temperature which is simply due to the increase of thermal conductivity. Figure $6 \mathrm{c}$, d depicts the effect of the nanoparticle diameter $\left(d_{p}\right)$ on the skin friction and the Nusselt number, respectively. Both the skin friction and the Nusselt number decrease with the increase in nanoparticle diameter. This is due to potential instability of nanofluid with larger nanoparticles. The settling velocity of nanoparticles $\left(V_{g}\right)$ can be calculated from Stokes law (only accounts for gravitational and buoyant forces) is as follows:

$V_{g}=\frac{2}{9}\left(\frac{\rho_{p}-\rho_{n f}}{\mu_{n f}}\right)\left(d_{p} / 2\right)^{2} g$,

where $g$ is the acceleration due to gravity. It can be noticed that from Eq. (23), that the stability of a suspension (defined by lower settling rates) improves if: (a) the viscosity of the suspension $\left(\mu_{n f}\right)$ is high (b) the density of the solid material $\left(\rho_{p}\right)$ is close to that of the fluid $\left(\rho_{n f}\right)$, and (c) the particle diameter $\left(d_{p}\right)$ is small.

Effect of nanolayer thermal conductivity and viscosity models

The effect of nanolayer to base fluid conductivity ratio $(\omega)$ on velocity profile $\left(f^{\prime}(\xi, \eta)\right)$ and temperature profile $(\theta(\xi, \eta))$ is shown in Fig. 7a, b, respectively. As we have already mentioned that $\omega(>1)$ is an empirical parameter which depends on the orderness of fluid molecules in the interface, nature and surface chemistry of nanoparticles. The value of $\omega$ should lies between 1 and 65.2529 $\left(1<\omega<k_{p} / k_{f}\right)$ for $\mathrm{Al}_{2} \mathrm{O}_{3}$ nanoparticles. It is observed that both velocity and temperature increase with the increase of nanolayer to base fluid conductivity ratio $(\omega)$ for the default parameters. It is due to the increase in thermal conductivity of nanofluid with the increase in $\omega$.

The effect of the nanolayer to base fluid conductivity ratio $(\omega)$ on the modified skin friction and the Nusselt number is shown in Fig. 7c, d, respectively. Both the 

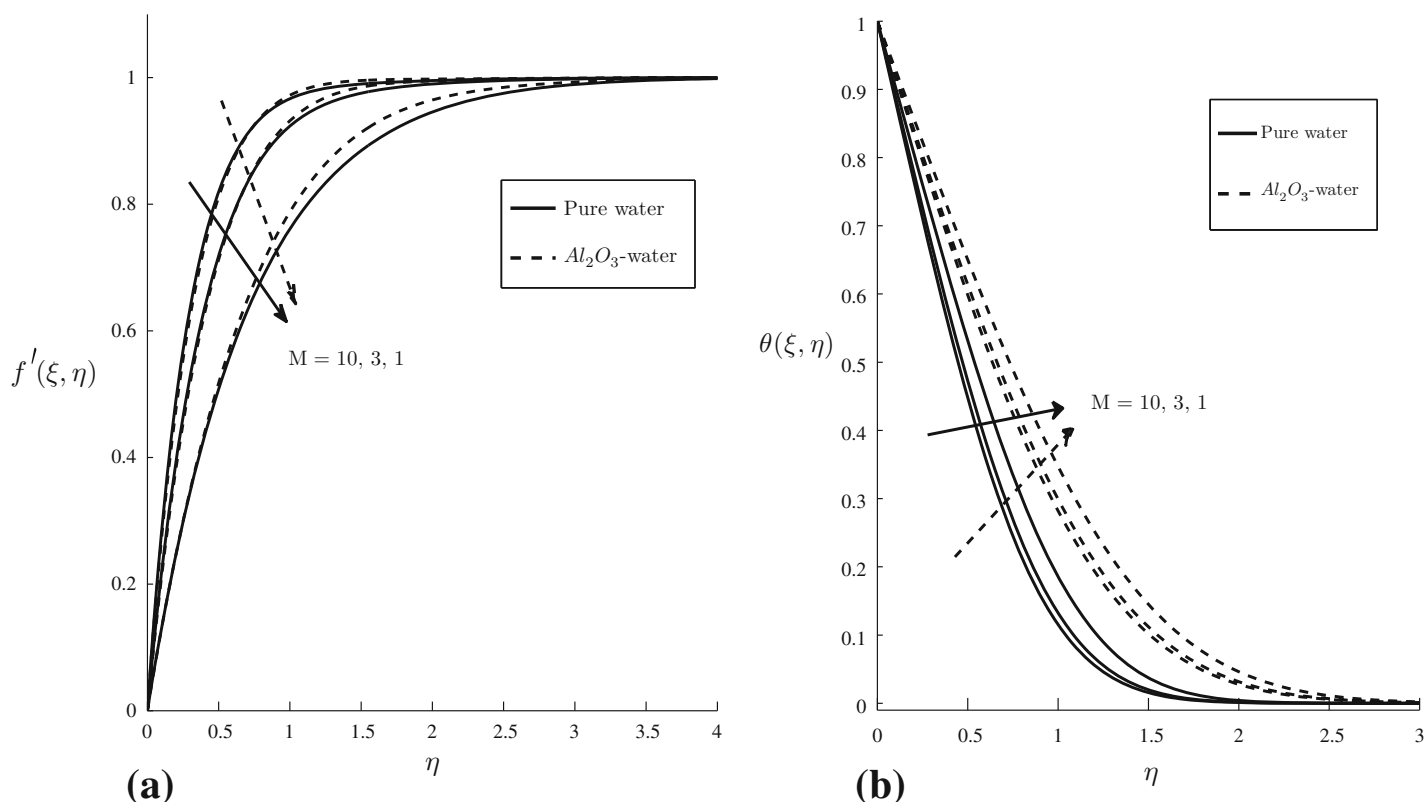

(a)

(b)
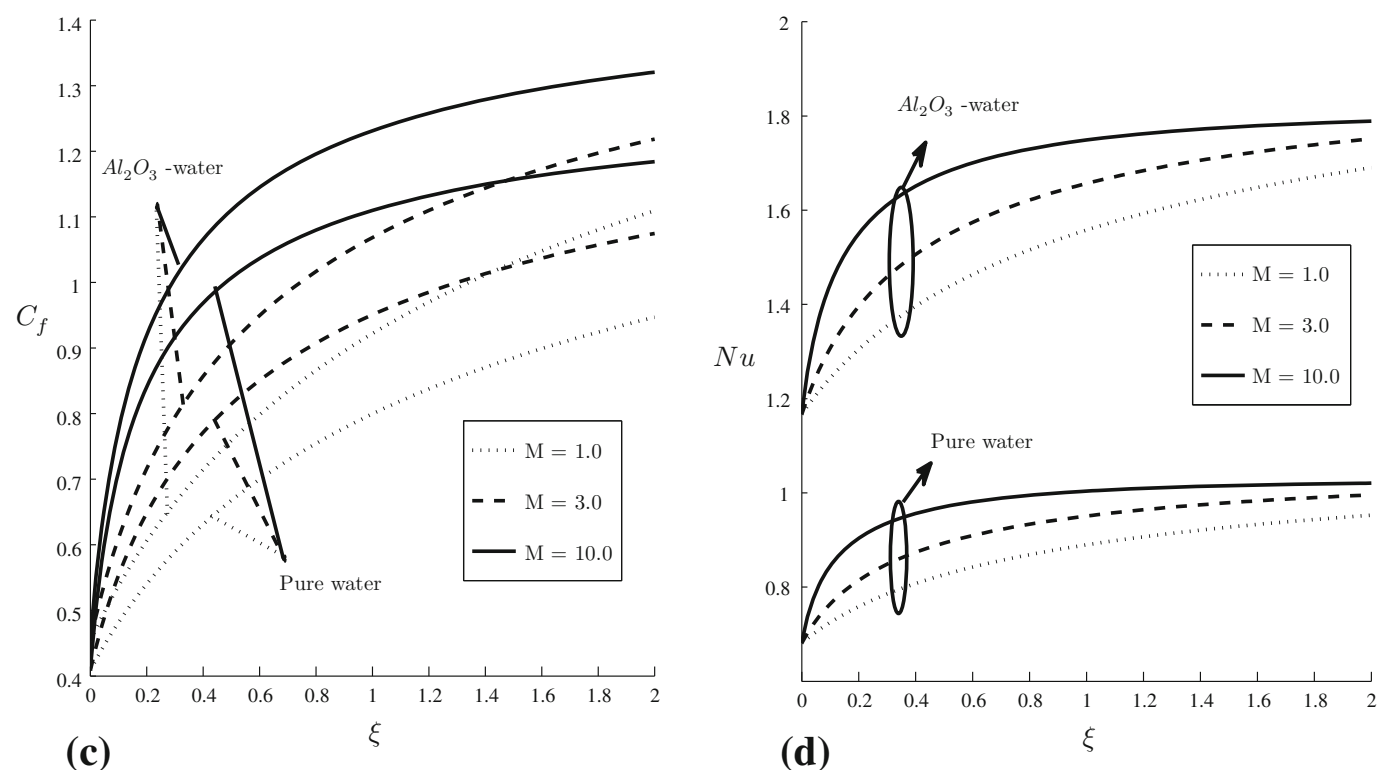

Fig. 5 Effect of magnetic parameter $(M)$ for pure water and $\mathrm{Al}_{2} \mathrm{O}_{3}$-water $(\phi=0.04)$. a Dimensionless velocity profiles. b Dimensionless temperature profiles. $\mathbf{c}$ Modified skin friction against the streamwise distance $\xi$. d Modified Nusselt number against the streamwise distance $\xi$

modified skin friction and the Nusselt number increase with the increase in this conductivity ratio. Thus, we can say that the value of nanolayer to base fluid conductivity ratio plays an important role. The effect of three different models for viscosity on velocity profile $\left(f^{\prime}(\xi, \eta)\right)$ and skin friction $(\theta(\xi, \eta))$ is shown in Fig. 8a, b, respectively. Different models for viscosity have been compared for this problem because of unavailability of most appropriate viscosity model. It is clear that for model I, the velocity is higher among all other models. This is due to lower viscosity in Model I as compared to other which also justifies the trend of skin friction.

\section{Effect of angle of inclination}

The effect of the angle of inclination $(\delta)$ on the modified skin friction and the Nusselt number is shown in Fig. 9a, $\mathrm{b}$, respectively. With an increase in plate inclination, the 


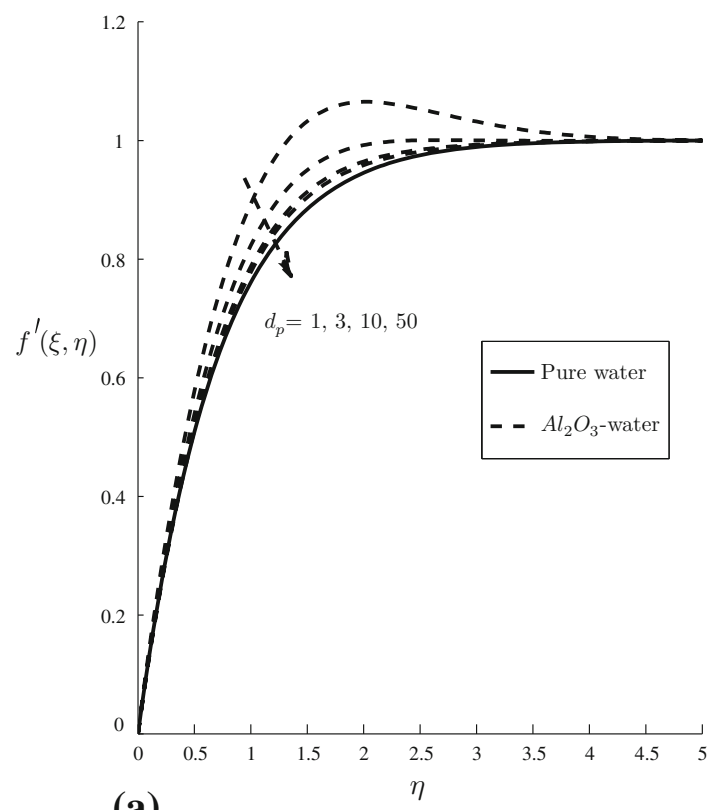

(a)

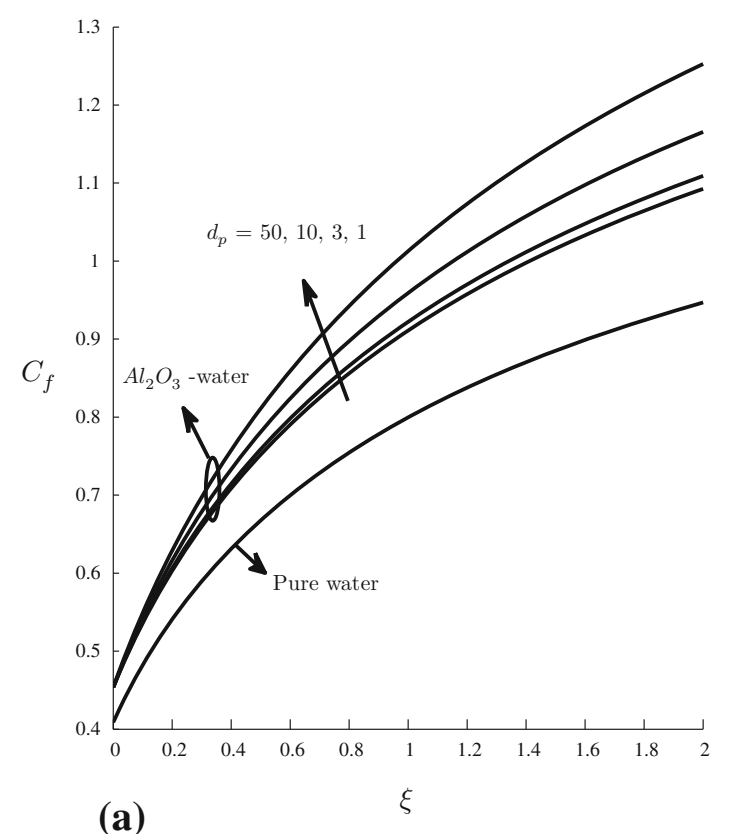

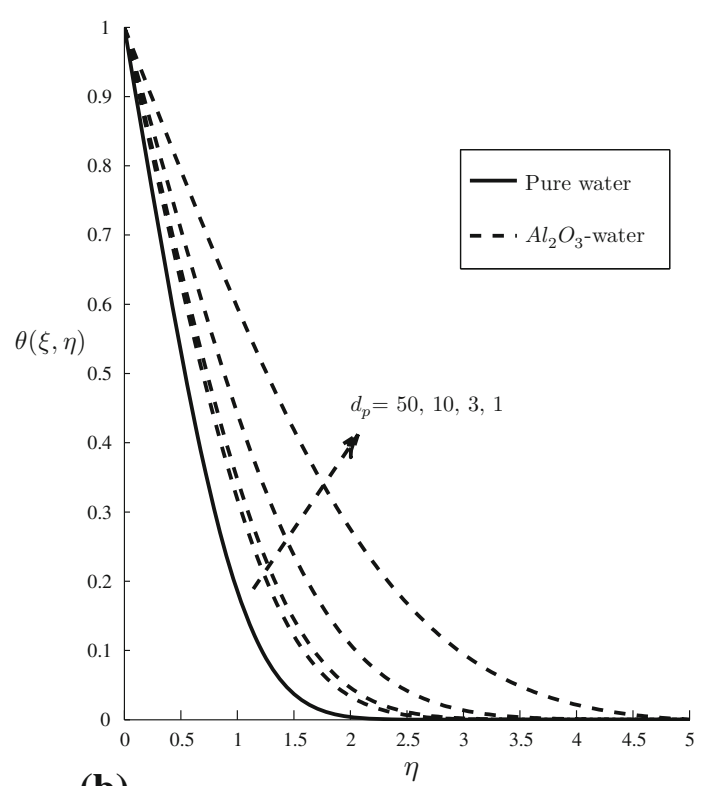

(b)

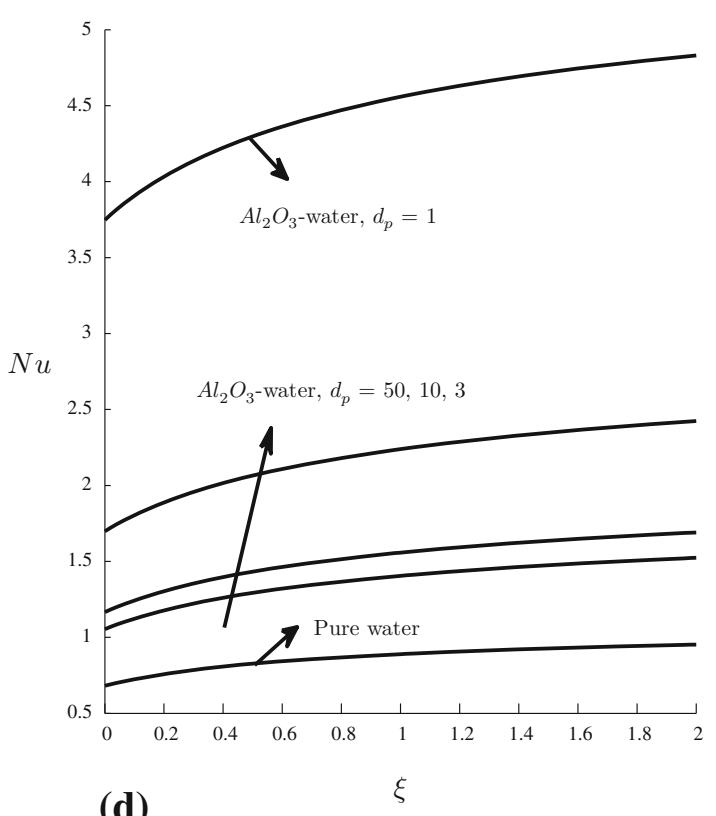

(d)

Fig. 6 Effect of nanoparticle diameter $\left(d_{p}\right)$ for pure water and $\mathrm{Al}_{2} \mathrm{O}_{3}-$ water $(\phi=0.04)$. a Dimensionless velocity profiles. b Dimensionless temperature profiles. $\mathbf{c}$ Modified skin friction against the streamwise distance $\xi$. d Modified Nusselt number against the streamwise distance $\xi$

velocity decreases. The case of $\delta=0$ corresponds to the vertical plate configuration and for this scenario, the velocity is found to be maximum. For the case $\delta \rightarrow \pi / 2$, $\cos (\pi / 2) \rightarrow 0$, i.e., buoyancy effects vanish (horizontal plate scenario, where the gravity field is normal to the plate surface and exerts no effect on the flow). The plate orientation is simulated via the modified buoyancy term, $\frac{\sigma B_{0}^{2}}{\rho}\left(u-u_{\infty}\right) \cos (\delta)$, arising in the momentum boundary layer Eq. (2). As $\delta$ increases, $\cos (\delta)$ decreases. This causes the buoyancy effect to be depleted with increasing inclination of the plate. The effects of three lateral mass flux (transpiration) cases at the plate surface, i.e., of suction $\left(f_{w}=0.25\right)$, solid wall $\left(f_{w}=0\right)$ and injection 

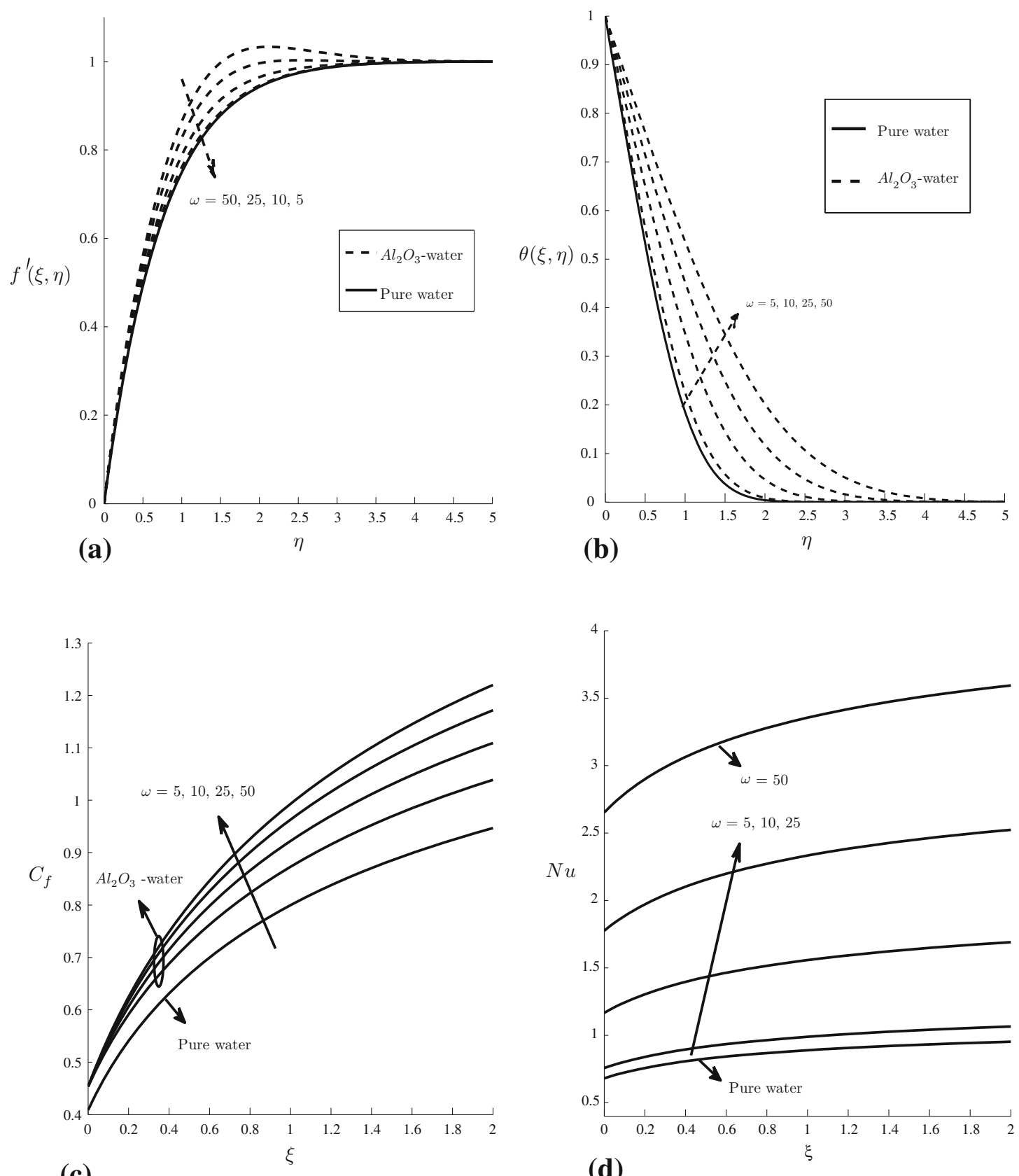

(c)

(d)

Fig. 7 Effect of nanolayer to base fluid conductivity ratio $(\omega)$ for pure water and $\mathrm{Al}_{2} \mathrm{O}_{3}$-water $(\phi=0.04)$. a Dimensionless velocity profiles. b Dimensionless temperature profiles. c Modified skin

friction against the streamwise distance $\xi$. d Modified Nusselt number against the streamwise distance $\xi$

$\left(f_{w}=-0.25\right)$ on Nusselt number $(\mathrm{Nu})$ have been shown in Fig. 10 .

Figure 11 depicts the variation of average Nusselt number $\left(\mathrm{Nu}_{\text {avg }}\right)$ with $d_{p}$ for different $\omega$. Average Nusselt number decreases exponentially with the decrease of nanoparticle size for each case. In Fig. 12, the average Nusselt number has

been plotted against the volume fraction $(\phi)$ ranging from $0 \leq \phi \leq 0.04$ for different models of viscosity. The graph shows that the average Nusselt number increases linearly with the volume fraction. Moreover, average Nusselt number $\left(\mathrm{Nu}_{\text {avg }}\right)$ increases more sharply with the volume fraction for model I as compared to other models. 

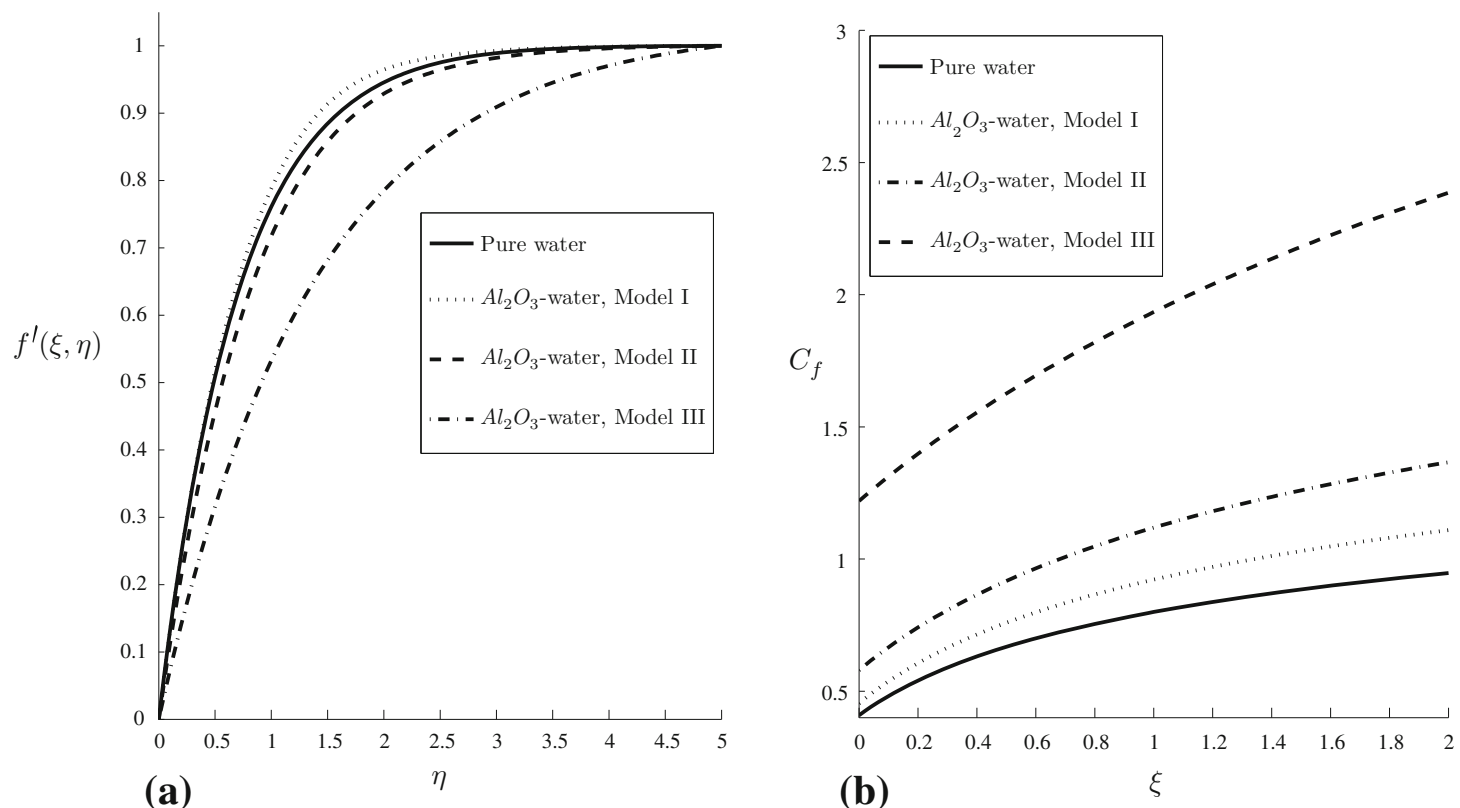

Fig. 8 Effect the different models for pure water and $\mathrm{Al}_{2} \mathrm{O}_{3}$-water $(\phi=0.04)$. a Dimensionless velocity profiles. b Modified skin friction against the streamwise distance $\xi$

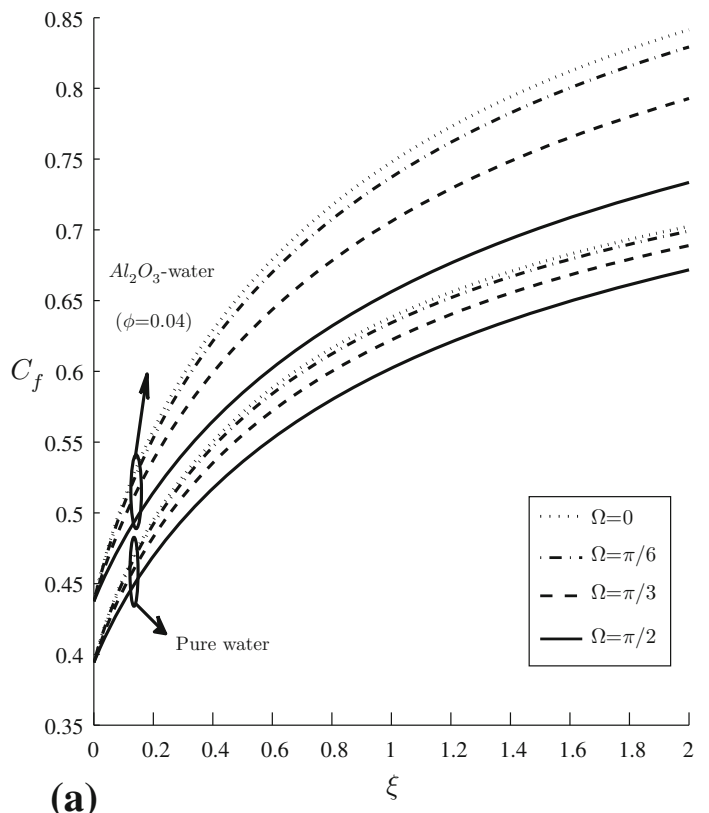

(a)

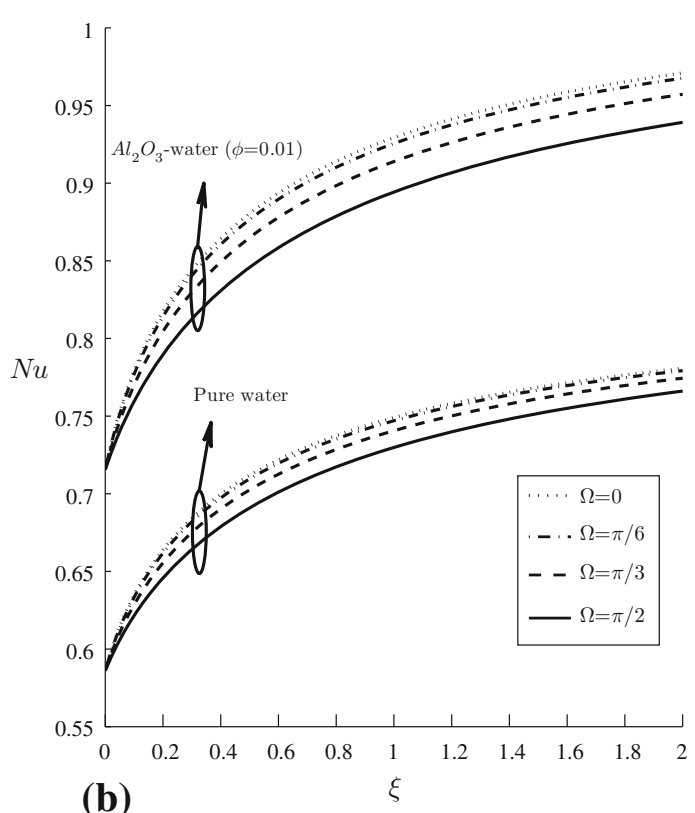

(b)

Fig. 9 Effect of angle of inclination $(\delta)$ for pure water and $\mathrm{Al}_{2} \mathrm{O}_{3}$-water $(\phi=0.04)$. a Modified skin friction against the streamwise distance $\xi$. b Modified Nusselt number against the streamwise distance $\xi$

\section{Conclusions}

In this present paper, mixed convection $\mathrm{Al}_{2} \mathrm{O}_{3}$-water nanofluid flows in two-dimensional vertical plate have been investigated to study heat transfer enhancement due to application of the nanoparticles to the base fluid. Numerical results for the local Nusselt number and local skin friction, temperature profile and velocity profile are 


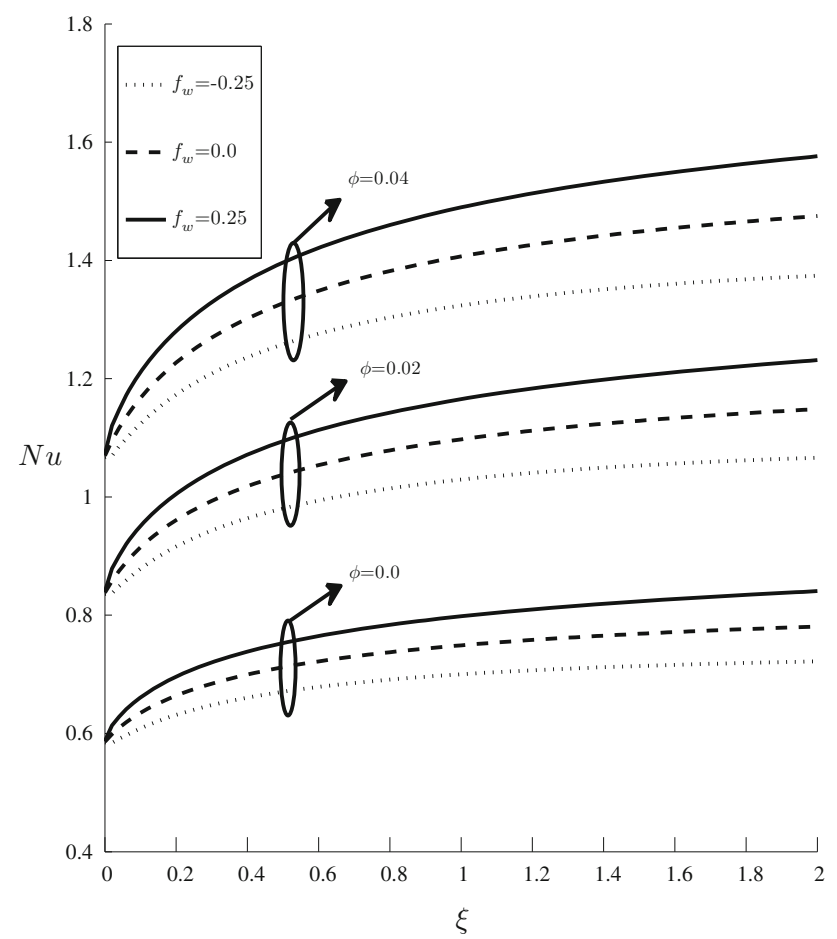

Fig. 10 Effect of suction/injection parameter $\left(f_{w}\right)$ on Nusselt number against the streamwise distance $(\xi)$ for different nanoparticle volume fraction $(\phi)$

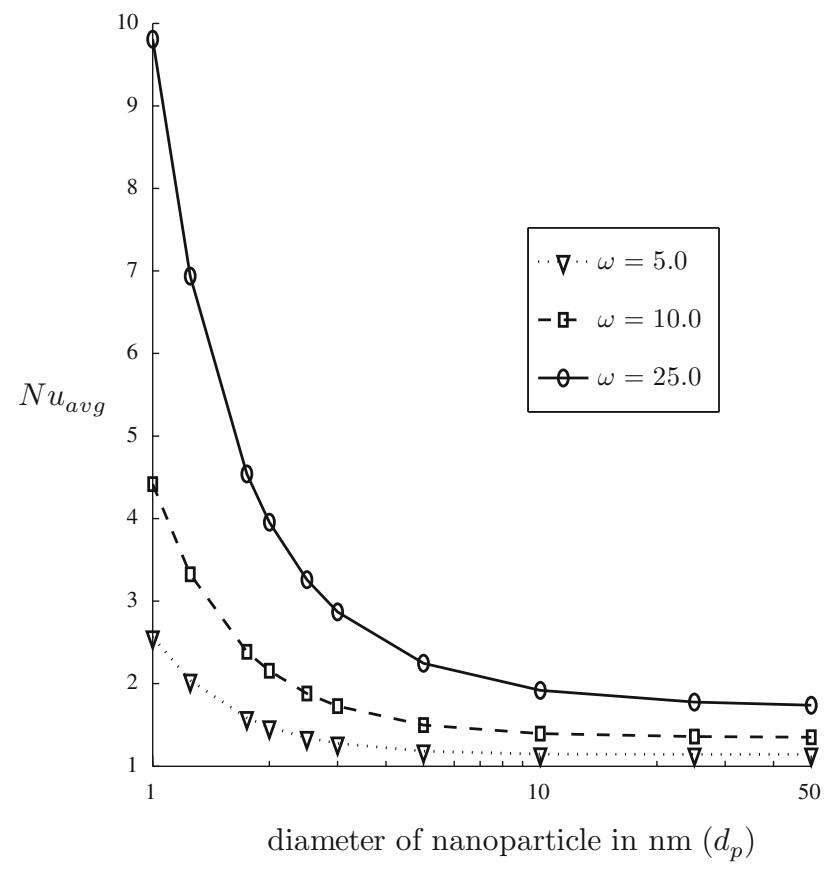

Fig. 11 Variation of average Nusselt number $\left(\mathrm{Nu}_{\text {avg }}\right)$ with diameter of nanoparticle in $\mathrm{nm}\left(d_{p}\right)$ for different nanolayer and base fluid conductivity ratio $(\omega)$

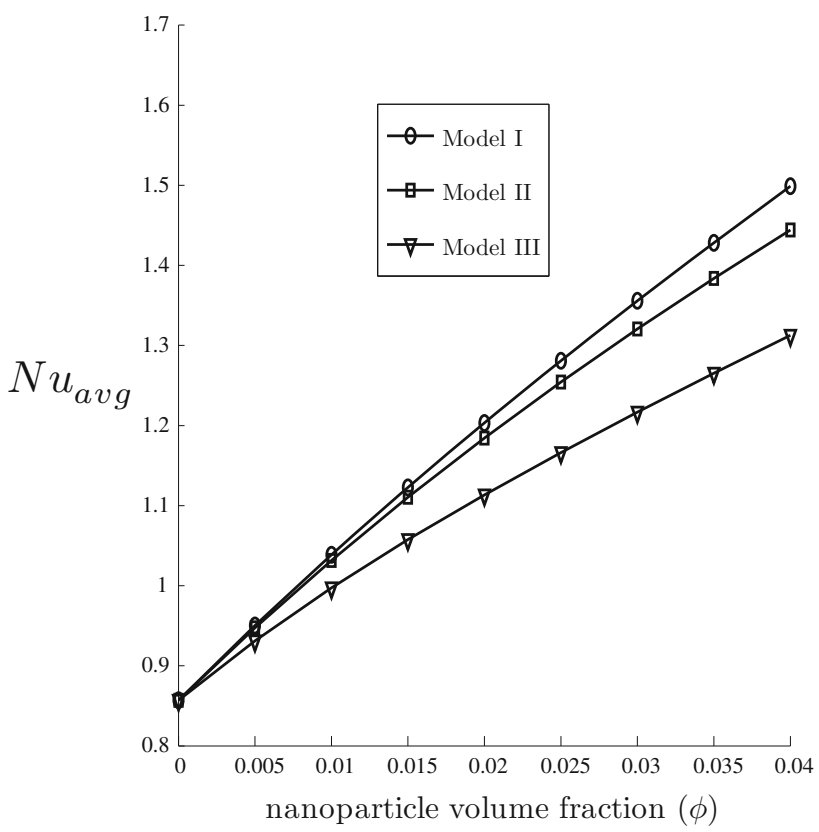

Fig. 12 Variation of average Nusselt number $\left(\mathrm{Nu}_{\mathrm{avg}}\right)$ with nanoparticle volume fraction $(\phi)$ for different models

presented graphically for various governing parameters. The average Nusselt number has also been compared for different nanoparticle diameter and volume fraction. The main conclusions are as follows:

1. At a given Richardson number (Ri) the enhancement in heat transfer has been noted with the increase in magnetic field, both for pure water and nanofluids. But the effect is more pronounced with nanofluids.

2. Increase in nanoparticle diameter $\left(d_{p}\right)$ decreases the surface heat transfer. Moreover, it does not have any significant change on the heat transfer beyond $25 \mathrm{~nm}$ at a constant Richardson number (Ri) and magnetic field.

3. Higher the value of nanolayer to base fluid conductivity ratio $(\omega)$, more will be the heat transfer enhancement. It has also been shown that the heat transfer increases with the increase of nanoparticle volume fraction $(\phi)$.

4. Both the angle of inclination of the plate $(\delta)$ and transpiration parameter $\left(f_{w}\right)$ have prominent effect in the case of nanofluids.

5. Average Nusselt number $\left(\mathrm{Nu}_{\mathrm{avg}}\right)$ is higher for classical viscosity model (model I) assumptions as compared to other.

Open Access This article is distributed under the terms of the Creative Commons Attribution License which permits any use, distribution, and reproduction in any medium, provided the original author(s) and the source are credited. 


\section{References}

Abdelkhalek MM (2006) The skin friction in the MHD mixed convection stagnation point with mass transfer. Int Commun Heat Mass Transf 33(2):249-258

Aydin O, Kaya A (2007) Mixed convection of a viscous dissipating fluid about a vertical flat plate. Appl Math Model 31(5):843-853

Aydin O, Kaya A (2009a) MHD mixed convection of a viscous dissipating fluid about a permeable vertical flat plate. Appl Math Model 33(11):4086-4096

Aydin O, Kaya A (2009b) MHD mixed convective heat transfer flow about an inclined plate. Heat Mass Transf 46(1):129-136

Bhargava R, Rana P (2011) Finite element solution to mixed convection in mhd flow of micropolar fluid along a moving vertical cylinder with variable conductivity. Int J Appl Math Mech 7:29-51

Brinkman HC (1952) The viscosity of concentrated suspensions and solutions. J Chem Phys 20(4):571-581

Chamkha AJ, Mujtaba M, Quadri A, Issa C (2003) Thermal radiation effects on MHD forced convection flow adjacent to a nonisothermal wedge in the presence of a heat source or sink. Heat Mass Transf 39(4):305-312

Choi SUS (1995) Enhancing thermal conductivity of fluids with nanoparticles in developments and applications of non-Newtonian flows. In: Siginer DA, Wang HP (eds) ASME, FED 231/, vol 66, pp 99-105

Dettmer W, Peric D (2006) A computational framework for fluidrigid body interaction: finite element formulation and applications. Comput Methods Appl Mech Eng 195(13-16):1633-1666

Hamad MAA (2011) Analytical solution of natural convection flow of a nanofluid over a linearly stretching sheet in the presence of magnetic field. Int Commun Heat Mass Transf 38(4):487-492

Hamilton RL, Crosser OK (1962) Thermal conductivity of heterogeneous two-component systems. Ind Eng Chem Fundam 1(3):187-191

Hansbo A, Hansbo P (2004) A finite element method for the simulation of strong and weak discontinuities in solid mechanics. Comput Methods Appl Mech Eng 139(33-35):3523-3540

Hashimoto T, Fujimura M, Kawai H (1980) Domain-boundary structure of styrene-isoprene block copolymer films cast from solutions. 5. Molecular-weight dependence of spherical microdomains. Macromolecules 13(6):1660-1669

Koo J, Kleinstreuer C (2004) A new thermal conductivity model for nanofluids. J Nanopart Res 6(6):577-588

Leong KC, Yang C, Murshed SMS (2006) A model for the thermal conductivity of nanofluids-the effect of interfacial layer. J Nanopart Res 8(2):245-254

Maxwell JC (1873) A treatise on electricity and magnetism, vol 1. Clarendon Press, Oxford
Murshed SMS, Leong KC, Yang C (2008) Investigations of thermal conductivity and viscosity of nanofluids. Int $\mathrm{J}$ Therm Sci 47(5):560-568

Nield DA, Kuznetsov AV (2003) Boundary-layer analysis of forced convection with a plate and porous substrate. Acta Mech 166(1):141-148

Oztop HF, Abu-Nada E (2008) Numerical study of natural convection in partially heated rectangular enclosures filled with nanofluids. Int J Heat Fluid Flow 29(5):1326-1336

Pak BC, Cho YI (1998) Hydrodynamic and heat transfer study of dispersed fluids with submicron metallic oxide particles. Exp Heat Transf: Int J 11(2):151-170

Rana P, Bhargava R (2011) Numerical study of heat transfer enhancement in mixed convection flow along a vertical plate with heat source/sink utilizing nanofluids. Commun Nonlinear Sci Numer Simul 16:4318-4334

Rana P, Bhargava R, Bég OA (2012) Numerical solution for mixed convection boundary layer flow of a nanofluid along an inclined plate embedded in a porous medium. Comput Math Appl 64(9):2816-2832

Rana P, Bhargava R, Bég OA (2013) Finite element modeling of conjugate mixed convection flow of $\mathrm{Al}_{2} \mathrm{O}_{3}$ water nanofluid from an inclined slender hollow cylinder. Phys Scripta 87:055005

Reddy JN (1985) An introduction to the finite element method. McGraw-Hill Book Co, New York

Shahidian A, Ghassemi M, Mohammadi R (2012) Effect of nanofluid properties on magnetohydrodynamic pump (MHD). Adv Mater Res 403:663-669

Tillman P, Hill JM (2007) Determination of nanolayer thickness for a nanofluid. Int Commun Heat Mass Transf 34(4):399-407

Tiwari RK, Das MK (2007) Heat transfer augmentation in a two-sided lid-driven differentially heated square cavity utilizing nanofluids. Int J Heat Mass Transf 50(9):2002-2018

Wang BX, Zhou LP, Peng XF (2003) A fractal model for predicting the effective thermal conductivity of liquid with suspension of nanoparticles. Int J Heat Mass Transf 46(14):2665-2672

Wang X, Xu X, Choi SUS (1999) Thermal conductivity of nanoparticle-fluid mixture. J Thermophys Heat Transf 13(4): 474-480

Watanabe T, Pop I (1994) Thermal boundary layers in magnetohydrodynamic flow over a flat plate in the presence of a transverse magnetic field. Acta Mech 105(1):233-238

Xuan Y, Li Q (2000) Heat transfer enhancement of nanofluids. Int J Heat Fluid Flow 21(1):58-64

Xue Q, Xu WM (2005) A model of thermal conductivity of nanofluids with interfacial shells. Mater Chem Phys 90(2):298-301

Yih KA (1999) MHD forced convection flow adjacent to a nonisothermal wedge. Int Commun Heat Mass Transf 26(6): 819-827 